\title{
ERRATUM
}

\section{Real-time single-molecule imaging of quantum interference}

Thomas Juffmann, Adriana Milic, Michael Müllneritsch, Peter Asenbaum, Alexander Tsukernik, Jens Tüxen, Marcel Mayor, Ori Cheshnovsky and Markus Arndt

Nature Nanotechnology 7, 297-300 (2012); published online 25 March 2012; corrected after print 25 July 2012.

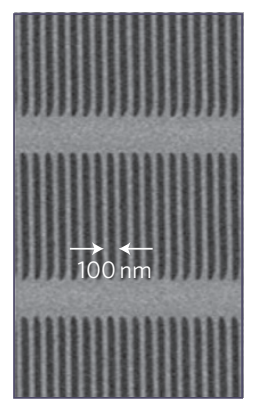

In the version of this Letter originally published, in Fig. 1c, the two white arrows were incorrectly positioned; they should have appeared as shown here. This has now been corrected in the HTML and PDF versions. 